DOI: $10.1590 / 1089-6891 v 16 i 113679$

MEDICINA VETERINÁRIA

\title{
PESQUISA DE SALMONELLA EM MUTUNS (Mitu mitu) MANTIDOS EM \\ CATIVEIRO
}

\section{SURVEY OF SALMONELLA IN CURASSOWS BREEDING CENTER OF WILD}

\author{
ANIMALS
}

\author{
Andréia Nakashima Vaz ${ }^{1}$ \\ Alexandre Paulo Armando ${ }^{2}$ \\ Andréa Rentz Ribeiro ${ }^{3}$ \\ Fábio Tavares Zancan 4 \\ Marcelo Landim Brisola ${ }^{3}$
}

1Bióloga, Doutora, Faculdade de Medicina Veterinária e Zootenia,USP, Pirassununga, SP, Brasil acnvaz@usp.br

2Veterinário do Zooparque, Itatiba, SP, Brasil.

${ }^{3}$ Professores Doutores da Pontifícia Universidade Católica de Minas Gerais, Poços de Caldas, MG, Brasil

4Pós-graduando da Universidade Estadual Paulista, Jaboticabal, SP, Brasil.

\section{Resumo:}

Foram colhidas 50 amostras de fezes de mutuns do Criadouro Científico e Cultural Poços de Caldas. A amostras foram enriquecidas em meio caldo Tetrationato e Selenito-Cistina e plaqueadas em Salmonella Shigella (SS), Mac Conkey (MC), Endo-C (EC), Verde Brilhante (VB) e Eosina Azul de Metileno (EMB), a $37^{\circ}$ C por $24 \mathrm{~h}$. Colônias suspeitas de Salmonella spp foram inoculadas em tubos contendo Ágar Tríplice Açúcar Ferro (TSI) e incubadas a $37^{\circ} \mathrm{C}$ por $24 \mathrm{~h}$. Os tubos com crescimento característico foram submetidas ao teste de aglutinação em lâmina com soros polivalentes somático e flagelar. Os meios SS, MC e VB foram os mais eficientes para o cultivo, sendo 6\% das amostras, positivas para Salmonella spp. Sabendo-se que as aves são reservatórios importantes de Salmonella spp e que esta pode representar um alto risco para a saúde humana, há a necessidade de implantação de uma rotina de limpeza dos recintos para evitar contaminação entre os recintos e o consequente carreamento destes micro-organismos, pelos tratadores, até suas residências ou outros recintos. A presença da Salmonella spp em criadouros pode ser responsável pela menor eclodibilidade dos ovos, prejudicando o objetivo da entidade, que visa o estudo e a manutenção das diferentes espécies de aves silvestres.

Palavras-chave: cultura microbiológica; fezes; mutum; Salmonella.

\begin{abstract}
:
We collected 50 samples of curasow feces from the Scientific and Cultural Breeding Center in the city of Poços de Caldas. The samples were enriched in broth medium Tetrationato and Cystineselenite and plated on Salmonella Shigella (SS), Mac Conkey (MC), endo-C (EC), Brilliant Green (VB) and Eosyn Methilen Blue EMB, remaining at $37{ }^{\circ} \mathrm{C}$ for $24 \mathrm{~h}$. Colonies suspected of Salmonella were inoculated in tubes containing Agar Triple Sugar Iron (TSI) and again incubated at $37{ }^{\circ} \mathrm{C}$ for $24 \mathrm{~h}$. Tubes with characteristic growth were submitted to slide agglutination test with polyvalent somatic and flagellar serum. The medium SS, MC and VB were the most efficient for growing, and $36 \%$ of samples were positive for Salmonella spp. As birds are important reservoirs of
\end{abstract}


Salmonella spp and it may represent a high risk to human health, there is a need to implement a cleaning routine in enclosures avoiding contamination between the enclosures and the consequent entrainment of these micro-organisms, by the keepers until their homes or other venues. The presence of Salmonella in breeding centers may be responsible for lower hatchability of eggs, undermining the purpose of the entity, which is to study and maintain the various birds species.

Keywords: curassows; feces; microbiological culture; Salmonella.

Recebido em: 04 abr. 2011.

Aceito em:17 nov. 2014.

\section{Introdução}

A salmonelose é uma doença provocada por bactérias do gênero Salmonella e de diversos sorovares, encontrados em animais e até mesmo no homem. As informações sobre a ocorrência e a distribuição dos sorotipos são essenciais para relacionar os possíveis reservatórios que possam ser responsáveis pela transmissão desse agente ${ }^{(1,2)}$. A salmonelose pode representar um sério problema de saúde pública, tendo como agravante a resistência aos antimicrobianos presentes no mercado ${ }^{(3)}$. Dentre as enfermidades causadas pela Salmonella em aves, podem-se destacar a pulorose, o tifo aviário e o paratifo aviário, que podem causar diarréias, alta mortalidade e baixa taxa de natalidade. Algumas aves não desenvolvem a doença clínica, apesar de a bactéria ser isolada em cultura de órgãos, como o baço, o fígado e, em algumas ocasiões, os ovários ${ }^{(4,5)}$.

Muitas aves acometidas não apresentam sintomas, mas transmitem as bactérias pelos ovos ou fezes. As fezes contaminam o ambiente e a Salmonela pode permanecer por longo período de tempo em um galpão despovoado, embora não apresentem formas de resistência. Daí a importância da limpeza, desinfecção ambiental, vazio sanitário e combate a roedores, como ressaltado por Silva e Duarte $^{(6)}$.

Acredita-se que as aves silvestres não tenham um papel importante na epidemiologia da salmonelose humana, porém, quando um grande número de aves vive num mesmo local, como é o caso de criadouros, comerciais ou não, elas podem representar um potencial risco para a saúde do ser humano e de outros animais ${ }^{(7,8)}$. Como o criadouro Científico e Cultural Poços de Caldas abriga cerca de 300 espécies de aves silvestres, é importante a verificação da ocorrência de Salmonella spp. Dentre as várias espécies, o mutum foi a primeira ave escolhida devido à facilidade de manejo nos recintos.

O objetivo deste estudo foi verificar a ocorrência de Salmonella spp. em mutuns do Criadouro Científico e Cultural Poços de Caldas.

\section{Material e Métodos}

As aves ficam alojadas em recintos de alvenaria, com frente em tela de arame e cobertura parcial de telhas de amianto. Cada recinto abriga um único casal de mutuns e, para evitar que outras aves invadam o espaço, os recintos foram cobertos com tela de arame. No período de março a maio de 2005, foram realizadas cinco coletas de amostras de fezes de mutuns. Estas amostras de fezes, provenientes do chão e poleiro, foram coletadas em swab estéril, embebido em PBS pH neutro, 
também estéril. As coletas foram realizadas a cada dez dias, em cinco recintos aleatórios, totalizando dez amostras por coleta, num total de 50 amostras.

$\mathrm{O}$ experimento foi realizado segundo o método proposto por Zancan et al. ${ }^{(9)}$, modificando-se somente o tempo de incubação. As amostras, embebidas em PBS (pH 7), foram enriquecidas em meio caldo Tetrationato e Selenito-Cistina, permanecendo a $37{ }^{\circ} \mathrm{C}$ por 24 horas. Após o enriquecimento, foram plaqueadas em Salmonella Shigella (SS), Mac Conkey (MC), Endo-C (EC), Verde Brilhante (VB) e Eosina Azul de Metileno (BEM), permanecendo a $37^{\circ} \mathrm{C}$ por $24 \mathrm{~h}$.

As colônias foram visualmente analisadas e aquelas sugestivas para Salmonella spp foram inoculadas em tubos contendo Ágar Tríplice Açúcar Ferro (TSI) e novamente incubadas a $37{ }^{\circ} \mathrm{C}$ por 24h. Os tubos com crescimento característico foram submetidos ao teste de aglutinação em lâmina com soros polivalentes somático e flagelar.

\section{Resultados}

O isolamento foi obtido em ambos os meios de enriquecimento utilizados (tetrationato e selenitocistina) e os meios de plaqueamento MacConkey, Verde Brilhante e Salmonella-Shigella, combinados com os meios de enriquecimento anteriormente referidos, foram os que isolaram a bactéria. Os resultados obtidos neste estudo podem ser visualizados na Tabela 1.

Tabela 1: Número de coletas realizadas tanto em poleiro quanto no chão assim como seus resultados positivos para Salmonellas

\begin{tabular}{|c|c|c|c|}
\hline Coletas & $\begin{array}{l}\mathrm{N}^{0} \text { de amostras poleiro/ } \mathrm{N}^{0} \\
\text { de amostras positivas }\end{array}$ & $\begin{array}{c}\mathrm{N}^{0} \text { de amostras chão/ } / \mathrm{N}^{0} \text { de } \\
\text { amostras positivas }\end{array}$ & $\begin{array}{l}\mathrm{N}^{0} \text { total de } \\
\text { positivos }\end{array}$ \\
\hline $1^{\mathrm{a}}$ & $5 / 1$ & $5 / 2$ & 3 \\
\hline $2^{a}$ & $5 / 0$ & $5 / 0$ & 0 \\
\hline $3^{\mathrm{a}}$ & $5 / 1$ & $5 / 3$ & 4 \\
\hline $4^{\mathrm{a}}$ & $5 / 0$ & $5 / 5$ & 5 \\
\hline $5^{\mathrm{a}}$ & $5 / 2$ & $5 / 3$ & 5 \\
\hline $\begin{array}{l}\text { Total de } \\
\text { amostras } \\
\text { positivas }\end{array}$ & 4 & 13 & 17 \\
\hline
\end{tabular}

Neste estudo, a Salmonella spp. esteve presente em 36\% das amostras avaliadas. Os resultados revelaram que houve uma maior presença de Salmonella nas amostras colhidas do chão (13 amostras) em relação àquelas colhidas dos poleiros (4 amostras). É importante ressaltar que estas amostras apresentavam-se em maior quantidade, com aspecto mais úmido, enquanto que no poleiro as fezes encontravam-se em menor quantidade e mais ressecadas. 


\section{Discussão}

O uso de mais de um meio de cultura favoreceu o isolamento da Salmonella spp, assim como descrito por Nascimento et al. ${ }^{(10)}$. O isolamento da bactéria confirmou sua presença em aves silvestres, neste caso, em mutuns. Kanashiro et al. ${ }^{(8)}$ observaram a presença da Salmonella em psitacídeos pertencentes a um criadouro comercial e Menão et al. ${ }^{(7)}$, em araras azuis apreendidas do tráfico.

A Salmonella pode ser introduzida nos criadouros por outros animais como ratos, mosquitos, fezes contaminadas e outras aves, como pombos ${ }^{(1,11)}$, podendo, também, afetar outras criações, trazendo perdas econômicas. Luque et al. ${ }^{(3)}$, ao avaliarem as causas de abortos em ovelhas em uma criação no Sul da Espanha, constataram que os pássaros silvestres eram os responsáveis pela infecção do rebanho.

Estudos com raposas (Vulpes vulpes) e tartarugas (de vida livre ou aquelas utilizadas como animal de estimação), mostraram a presença de Salmonella spp. nestes animais, indicando focos silvestres da presença da bactéria. Animais silvestres criados como de estimação podem ser fonte de infecção da doença para humanos ${ }^{(12,13)}$.

Um outro fator de risco é a alimentação utilizada. Gandolfi e $\operatorname{Ramos}^{(14)}$ realizaram um estudo que apontou o risco de as aves adquirirem o agente pela ingestão de rações contaminadas. A contaminação por Salmonella spp. nas rações pode acontecer com o uso de matérias-primas que não obedecem a um rígido controle higiênico-sanitário.

A presença da Salmonella spp em um criadouro que visa o estudo e a manutenção das diferentes espécies de aves silvestres pode ser responsável pela queda da eclodibilidade além de, sorrateiramente, se propagar para outras espécies animais, veiculada pelas fezes ou por seus subprodutos contaminados, visto que se trata de um microrganismos de ampla disseminação no ambiente e as aves, tanto as clinicamente sadias quanto as infectadas que sobreviveram a um surto, podem ser portadoras de salmonelas ${ }^{(2,15,16)}$.

\section{Conclusão}

A determinação dos sorovares (tipificação) das bactérias encontradas é fundamental para saber da patogenicidade destes agentes tanto para as aves quanto para os humanos. Esta é uma informação importante, visto que o criadouro é visitado por várias pessoas além daquelas que trabalham no local e que podem carregar este patógeno para suas famílias.

\section{Referências}

1.Gambiragi APOM, Salles RPR, Aguiar Filho JL, Oliveira WF, Maciel WC, Romão J M, Teixeira RSC. Salmonella sp. Em frangos de corte de um dia de idade na região metropolitana de Fortaleza-CE. Acta Scientiae Veterinariae. São Paulo, 2003;3(31):149-153. Disponível em: http://www.ufrgs.br/actavet/313/artigo565.pdf. Acesso em 10 janeiro 2015. 
2.Pereira RA, Canal CW, Schmidt V. Detecção de Salmonella Anatum em ema (Rhea americana). Ciência Rural, Santa Maria, 2008;38(3):823-825. Disponível em: http://dx.doi.org/10.1590/S0103$\underline{84782008000300038}$. Acesso em 10 janeiro 2015.

3.Luque I, Echeita A, León J, Herrera-León S, Tarradas C, González-Sanz R, Huerta B, Astorga R J. Salmonella Indiana as a cause of abortion in ewes: Genetic diversity and resistance patterns. Veterinary Microbiology. 2009;134:396-399. Disponível em: http://dx.doi.org/10.1016/j.vetmic.2008.08.015. Acesso em 10 janeiro 2015.

4.Hirsh DC, Zee YC. Microbiologia Veterinária. $1^{a}$.ed. v.1. Rio de Janeiro: Guanabara Koogan, 2003. Cap. 10, p. 69-73.

5.Berchieri JR. A, Oliveira GH, Pinheiro LS, Barrow PA. Experimental Salmonella gallinarum infection in light laying hen lines. Brazilian Journal of Microbiology, 2000;31(1):50-52. Disponível em: http://dx.doi.org/10.1590/S1517-83822000000100012.

6.Silva EM, Duarte A. Salmonella Enteritidis em Aves: Retrospectiva no Brasil. Revista Brasileira de Ciência Avícola, Campinas, 2002;4(2):85-100. Disponível em: http://dx.doi.org/10.1590/S1516635X2002000200001. Acesso em 10 janeiro 2015.

7.Menão MC, Bottino JÁ, Biasia I, Ferreira CSA, Calderaro FF, Tavechio AL, Fernandes S, Ferreira AJP. Infecção por Salmonella Typhimurium em Arara Azul (Anodorynchus hyacinthinus). Arquivo do Instituto Biologico, São Paulo, 2000;67(1): 43-47. Disponível em: http://www.biologico.sp.gov.br/docs/arq/V67_1/infeccao_salmonella.html. Acesso em 10 janeiro 2015.

8.Kanashiro AMI, Castro AGM, Cardoso ALSP, Tessari ENC, Tavechio AT. Persistência de Salmonella sp. após antibioticoterapia em psitacídeos pertencentes a um criadouro comercial. Arquivo do Instituto Biologico, São Paulo, 2002;69(2):99-101. Disponível em: http://www.biologico.sp.gov.br/docs/arq/V69 2/kanashiro.pdf. Acesso em 10 janeiro 2015.

9.Zancan FT, Berchieri JR. A, Fernandes SA, Gama NMS. Q. Salmonella spp investigation in transport boxes of day-old birds. Brazilian Journal of Microbiology. São Paulo, 2000;31:230-232. Disponível em: http://dx.doi.org/10.1590/S1517-83822000000300016.

10.Nascimento MS, Berchieri JR. A, Barbosa MD, Zancan FT, Almeida WAF. Comparação de meios de enriquecimento e de plaqueamento utilizados na pesquisa de Salmonella em carcaças de frangos e fezes de aves. Revista Brasileira de Ciência Avícola, 2000;2(1): 85-91. Disponível em: http://dx.doi.org/10.1590/S1516-635X2000000100012. Acesso em 10 janeiro 2015.

11.Lillehaug A, Monceyron Jonassen C, Bergsjo B, Hofshagen M, Tharaldsen J, Nesse L, Handeland K. Screening of Feral Pigeon (Columba Lívia), Mallard (Anas Platyrhynchos) and Graylag Goose (Anser anser) populations for Campylobacter, Salmonella, avian influenza virus and avian paramyxovirus. Acta Veterinarian Scandinavia. 2005;46:193-202.

12.Handeland K, Nesse LL, Lillehaug A, Vikoren T, Djonne B, Bergsjo B. Natural and experimental Salmonella Typhimurium infections in foxes (Vulpes vulpes). Veterinary Microbiology, 2008;132:129-134. Disponível em: http://dx.doi.org/10.1016/j.vetmic.2008.05.002.

13.Hidalgo-Vila J, Díaz-Paniagua C, Pérez-Santigosa N, Frutos-Escobar C, Herrero-Herrero A. Salmonella in free-living exotic and native turtles and in pet exotic turtles from SW spain. Research in Veterinary Science , 2008;85:449-452. Disponível em: http://digital.csic.es/bitstream/10261/63868/1/vetere.pdf. Acesso em 10 janeiro 2015.

14.Gandolfi CS, Ramos MIL. Salmonella sp em farinhas de origem animal utilizadas na elaboração de rações para aves. Higiene Alimentar, 2002;16(102/103):112-116.

15.Hofer EFSJS, Reis EMF. Prevalência de sorovares de Salmonella isolados de aves no Brasil. Pesquisa Veterinária Brasileira, 1997;2(17):55-62.

16.Santos LR, Dickel EL, Rodrigues LB, Nascimento VP, Ribeiro A R. Identificação de Salmonella enteitidis fagotipo $6 \mathrm{~A}$ em amostras de alimentos, humanos e materiais de origem avícola. Higiene Alimentar, 2004;18(119):64-67. 